\title{
Effect of Surfactant on Growth of ZnO Nanodumbbells and Their Characterization
}

\author{
Sunil Babu Eadi, Sungjin Kim, and Soon Wook Jeong \\ School of Advanced Materials \& Engineering, Kumoh National Institute of Technology, 61 Daehak-ro, \\ Gumi 39177, Republic of Korea \\ Correspondence should be addressed to Soon Wook Jeong; swjeong@kumoh.ac.kr
}

Received 15 March 2017; Accepted 22 May 2017; Published 25 July 2017

Academic Editor: Renal Backov

Copyright (C) 2017 Sunil Babu Eadi et al. This is an open access article distributed under the Creative Commons Attribution License, which permits unrestricted use, distribution, and reproduction in any medium, provided the original work is properly cited.

\begin{abstract}
We report the controlled synthesis of dumbbell shaped $\mathrm{ZnO}$ micro/nanostructures using anionic surfactant sodium dodecyl sulphate (SDS) by simple one-step hydrothermal method. The morphology changes of $\mathrm{ZnO}$ were characterized by using scanning electron microscopy, X-ray diffraction, and energy dispersive spectroscopy. It is found that the size of the dumbbell increased with increase in concentration of SDS. Systematic growth mechanism with increase of concentration of SDS polymer is studied. Our results will help in the growing face selective $\mathrm{ZnO}$ for many functional applications.
\end{abstract}

\section{Introduction}

Zinc oxide $(\mathrm{ZnO})$ is an important II-VI group semiconductor material. $\mathrm{ZnO}$ has a wide direct-band gap of $3.37 \mathrm{eV}$ and high-exciton-binding energy of $60 \mathrm{mV}$ at room temperature. $\mathrm{ZnO}$ has been extensively studied because of its fascinating wide range of applications such as chemical sensors and biosensors, piezoelectricity, optoelectronics, photocatalysis, and photoelectrochemical water splitting [1-8]. In many of the applications, $\mathrm{ZnO}$ functional properties are highly affected by the morphology of the nanostructure. In recent years, various research groups have reported the formation of different types of morphologies using surfactants. Surfactants (cationic, anionic) act as growth-directing agents in the reaction and show a dramatic effect on the shape and size of the $\mathrm{ZnO}$ nanostructures. Zhang et al. used polyvinyl pyrrolidone (PVP) as a growth directing reagent for preparing different type of $\mathrm{ZnO}$ morphology [9]. Tang et al. used surfactant cetyltrimethylammonium bromide (CTAB) for growing Zinc-HDS mesocrystal sheets [10]. In recent period, $\mathrm{ZnO}$ nanodisks and dumbbells shaped morphology have gained interest due to their potential application in the field of catalysis due to their face selective adsorption of various gases [11-13]. Thus, face selective growth of $\mathrm{ZnO}$ nanostructure can enhance the many application properties.
In this paper, we report the growth of $\mathrm{ZnO}$ nano/ microdumbbell nanostructures using SDS by simple one-step hydrothermal process. The effect of SDS concentration on the morphology of $\mathrm{ZnO}$ nanostructures has been studied.

\section{Experimental Section}

All the chemicals were of analytical reagent grade purchased from Sigma Aldrich and used as received without further purification. In a typical experimental procedure, $1 \mathrm{~g}$ of zinc nitrate hexahydrate $\mathrm{Zn}\left(\mathrm{NO}_{3}\right)_{2} \cdot 6 \mathrm{H}_{2} \mathrm{O}$ was dissolved in $50 \mathrm{ml}$ of deionized water in a beaker under magnetic stirring and $0.1 \mathrm{~g}$ of sodium dodecyl sulphate (SDS) anionic polymer was added. In this solution, $2 \mathrm{ml} \mathrm{NH}_{4} \mathrm{OH}$ solution was added drop by drop under vigorous stirring. The solutions were transferred to a $50 \mathrm{ml}$ autoclave and placed in a thermal oven for 10 hours at $150^{\circ} \mathrm{C}$. After cooling, the collected powder was washed with ethanol for 3 times and placed in oven for drying at $80^{\circ} \mathrm{C}$ overnight. To study the influence of SDS in the morphology, different amount of SDS was varied from $0.1 \mathrm{~g}$ to $0.5 \mathrm{~g}$. Surface morphology of the $\mathrm{ZnO}$ nanostructures was investigated by field emission scanning electron microscopy (FESEM, Hitachi S-4800). The structural properties were investigated by X-ray diffraction (XRD, Rigaku D/MAX-RC) using $\mathrm{Cu} \mathrm{K} \alpha$ radiation with a Ni filter. 


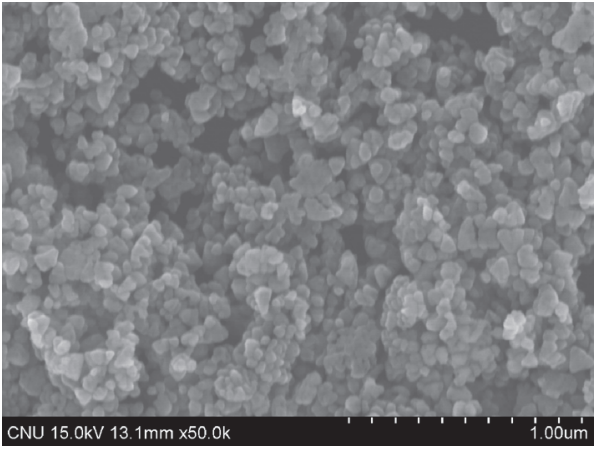

(a)

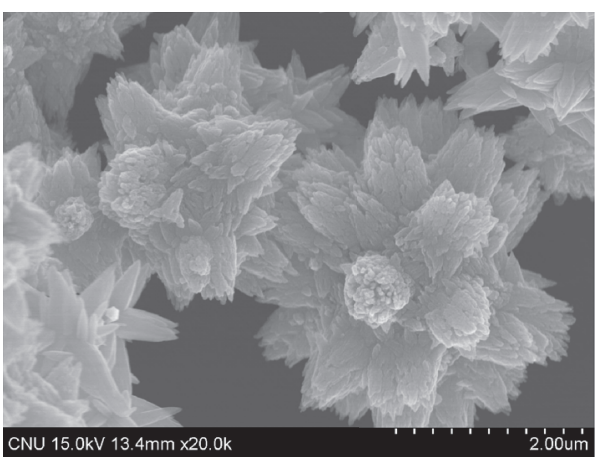

(c)

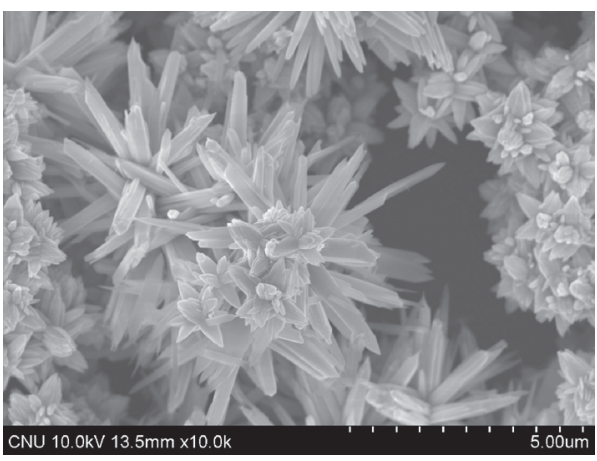

(e)

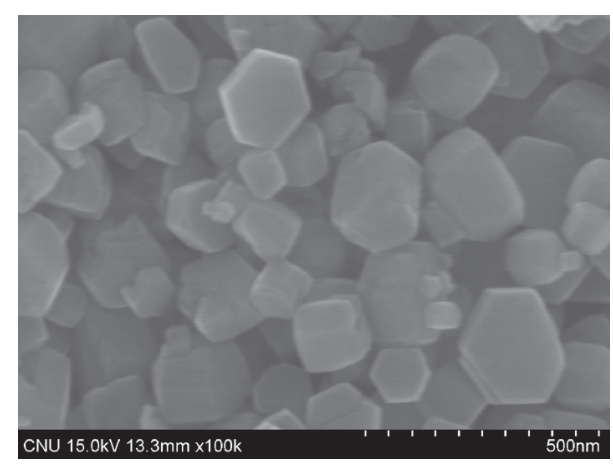

(b)

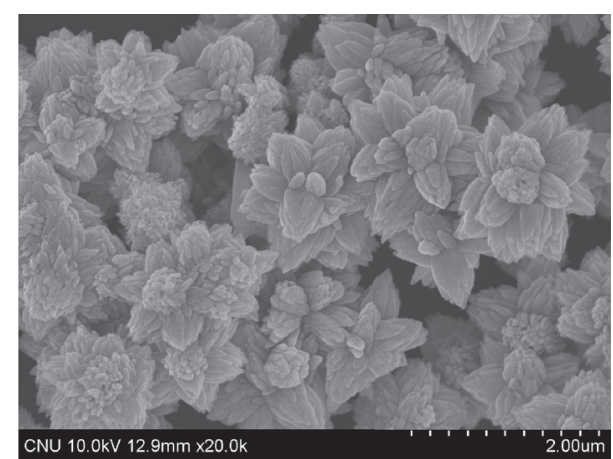

(d)

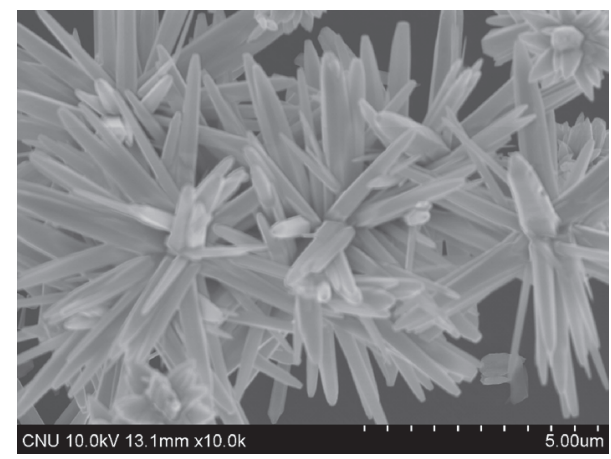

(f)

FIGURE 1: Typical FESEM images of $\mathrm{ZnO}$ nanostructures grown with different $\mathrm{NH}_{4} \mathrm{OH}$ concentrations of (a) $0.1 \mathrm{ml}$, (b) $0.5 \mathrm{ml}$, (c) $1.0 \mathrm{ml}$, (d) $2.0 \mathrm{ml}$, (e) $2.5 \mathrm{ml}$, and (f) $3.0 \mathrm{ml}$ and growth temperature and growth time of $150^{\circ} \mathrm{C}$ and 10 hours, respectively.

\section{Results and Discussion}

The shape and size controlled growth of $\mathrm{ZnO}$ in a hydrothermal process is affected by many factors such as temperature, concentration of precursors, surfactants, organic solvents, and growth time. To have proper understanding of SDS polymer effect on $\mathrm{ZnO}$ growth, first we studied the growth of $\mathrm{ZnO}$ nanostructures with effect to $\mathrm{NH}_{4} \mathrm{OH}$ concentration only and with no SDS. Figure 1 shows the FESEM of different $\mathrm{ZnO}$ nanostructures obtained with various concentrations of $\mathrm{NH}_{4} \mathrm{OH}$, for 10-hour growth time. It can be clearly seen that with increase in $\mathrm{NH}_{4} \mathrm{OH}$ concentration morphology changes from nanoparticles to nanorods. The size of the nanoparticles ranges within Avg. $50 \mathrm{~nm} \sim 70 \mathrm{~nm}$. Figure 1(a) shows the images of nanoparticles obtained at $0.5 \mathrm{ml}$ of $\mathrm{NH}_{4} \mathrm{OH}$, and Avg. particles sizes are ranges within $200 \mathrm{~nm} \sim 300 \mathrm{~nm}$. Further increase in $\mathrm{NH}_{4} \mathrm{OH}$ concertation in the solution morphology changes from nanoflowers. Figures 1(c)-1(f) show steady grow of nanoflowers with increase in the length of the rods, with Avg. nanorods size from $1 \mu \mathrm{m}, 1.5 \mu \mathrm{m}, 2 \mu \mathrm{m}$, and $3 \mu \mathrm{m}$, respectively.

The plot of $\mathrm{pH}$ of the solution with volume of $\mathrm{NH}_{4} \mathrm{OH}$ is shown in Figure 2. It can be noted that the $\mathrm{pH}$ of the solution increased with $\mathrm{NH}_{4} \mathrm{OH}$ concentration. Figure 3 shows the XRD patterns of the grown $\mathrm{ZnO}$ nanostructures with different $\mathrm{NH}_{4} \mathrm{OH}$ concentration in the solution. All the diffraction peaks can be indexed to know $\mathrm{ZnO}$ hexagonal wurtzite structure with major peaks of (100), (002), and (101), respectively. Furthermore, we studied the effect of SDS polymer with change in $\mathrm{NH}_{4} \mathrm{OH}$ concentration on $\mathrm{ZnO}$ 


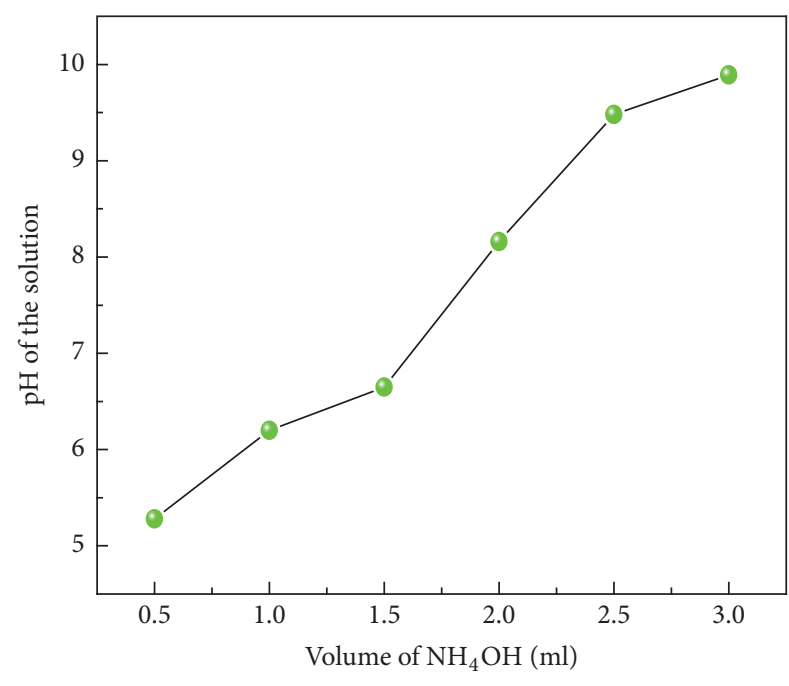

Figure 2: The plot of $\mathrm{pH}$ versus $\mathrm{NH}_{4} \mathrm{OH}$ concentration.

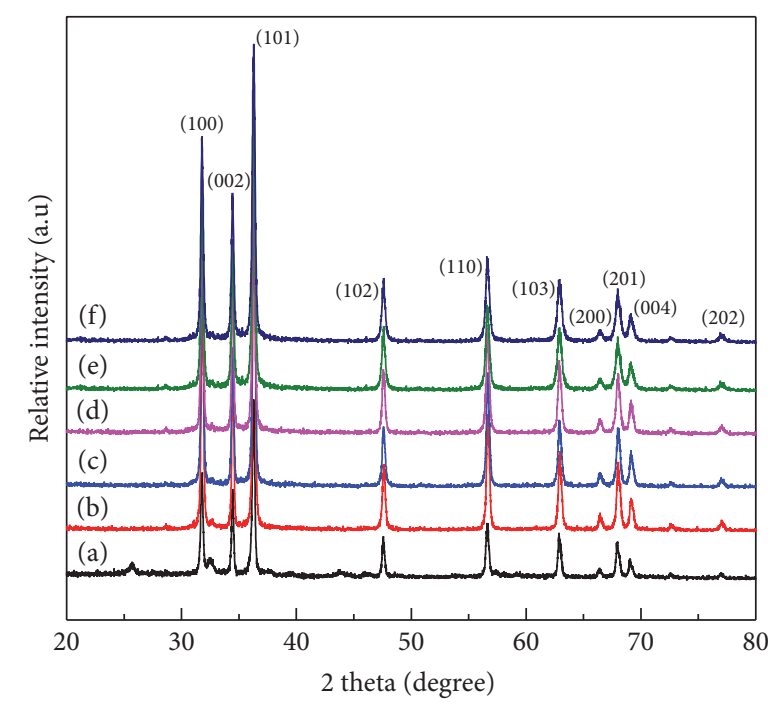

FIGURE 3: XRD profile of $\mathrm{ZnO}$ nanostructures grown with different $\mathrm{NH}_{4} \mathrm{OH}$ concentrations of (a) $0.1 \mathrm{ml}$, (b) $0.5 \mathrm{ml}$, (c) $1.0 \mathrm{ml}$, (d) $2.0 \mathrm{ml}$, (e) $2.5 \mathrm{ml}$, and (f) $3 \mathrm{ml}$.

nanostructures. Figure 4 shows the FESEM images of $\mathrm{ZnO}$ nanostructures grown with fixed SDS $(0.1 \mathrm{~g})$ and different $\mathrm{NH}_{4} \mathrm{OH}$ concentrations of (a) $0.1 \mathrm{ml}$, (b) $1.0 \mathrm{ml}$, and (f) $2.0 \mathrm{ml}$ for 10 -hour growth time and $150^{\circ} \mathrm{C}$ growth temperature. We can see that the SDS polymer affects the morphology different from the only $\mathrm{NH}_{4} \mathrm{OH}$ grown $\mathrm{ZnO}$ nanostructures. Figure 4(a) shows the rice type morphology, with Avg. length and diameter of $600 \mathrm{~nm}$ and $200 \mathrm{~nm}$, respectively. Figure 4(b) shows the agglomeration of rice beads into flower petals morphology. It is interesting to note that the morphology of rice beads changes to dumbbell shaped morphology as shown in Figure 4(c). To explore more on dumbbell shaped morphology of $\mathrm{ZnO}$ in our experiment, we fixed the temperature and concentration of zinc nitrate and $\mathrm{NH}_{4} \mathrm{OH}$, changed the SDS amount in the solution, and studied the effect on the final morphology of $\mathrm{ZnO}$. Figure 5 shows the FESEM images of $\mathrm{ZnO}$ nanostructures prepared in the experiment. Figure 5(a) shows the $\mathrm{ZnO}$ nanoflowers obtained without using any surfactant in the reaction. The nanoflowers basically consist of nanorods. The nanorods were grown to be $2 \mu \mathrm{m}$ in length and $300 \mathrm{~nm}$ in diameter. The morphology of the $\mathrm{ZnO}$ nanoflowers changed to nanodumbbells on addition of SDS surfactant. Figures 5(b)-5(f) show the FESEM images of nanodumbbells obtained at different concentration of SDS. The size of the dumbbells increased with the increase in the concentration of the SDS from $0.1 \mathrm{~g}$ to $0.5 \mathrm{~g}$. It was noticed that in Figure 5(b) when the concentration of SDS is $0.1 \mathrm{~g}$, the Avg. size of dumbbell is $900 \mathrm{~nm}$ and $2.5 \mu \mathrm{m}$ in diameter and height, respectively. In Figure 5(c), with increase in SDS to $0.2 \mathrm{~g}$, it was noticed that the diameter of nanodumbbell increased to $2 \mu \mathrm{m}$ and the change in height of the dumbbell was $2.8 \mu \mathrm{m}$ in length. At concentration $0.3 \mathrm{~g}$ of SDS, as shown in Figure 5(d), the diameter of nanodumbbell increased to $2.8 \mu \mathrm{m}$ in size and there was no considerable change in length of nanodumbbell, which specifies decrease in the aspect ratio. In further addition of $0.4 \mathrm{~g}$ SDS in the solution we obtained dumbbells with $4.4 \mu \mathrm{m}$ and $6.5 \mu \mathrm{m}$ in length and diameter, indicating growth along the side (100) faces increasing as shown in Figure 5(e). And finally at higher concentration $0.5 \mathrm{~g}$ of SDS, perfect hexagonal cylinder type morphology was observed. The hexagonal cylinders were highly symmetrical with $10 \mu \mathrm{m} \times 10 \mu \mathrm{m}$ heights and diameters, respectively. Figure 6 shows the XRD patterns of the grown $\mathrm{ZnO}$ nanostructures with and without the addition of SDS polymer in the solution. All the diffraction peaks can be indexed to know hexagonal wurtzite structure. The results indicated that the nanodumbbells consist of pure crystalline phase and the peak intensities of the prepared $\mathrm{ZnO}$ nanodumbbells increased with the concentration of the SDS indicating the formation of greater enhancement of crystallization. It is observed that the peak intensities of the nanoflowers are higher than the dumbbells structures.

It is evident that the SDS played important role in the formation of nanodumbbells and act as growth template. $\mathrm{CH}_{3}\left(\mathrm{CH}_{2}\right)_{11} \mathrm{OSO}_{3} \mathrm{Na}$ (SDS) in aqueous solution ionize into $\mathrm{Na}^{+}(\mathrm{S})$ and $\mathrm{CH}_{3}\left(\mathrm{CH}_{2}\right)_{11} \mathrm{OSO}_{3}{ }^{-}\left(\mathrm{DS}^{-}\right)$and attack on the polar faces of the $\mathrm{ZnO}$ and inhibit the growth along [0001] directions forming nanodumbbells. Without SDS, the formation of nanoflowers can be explained by Wolf's principle, a crystal growing under equilibrium conditions, crystal faces with maximum specific surface energy $(\sigma h k l)$ values grow at maximum rate values compared to their faces with minimum $\sigma h k l$. In case of $\mathrm{ZnO}$, the polar (0001) face of $\mathrm{ZnO}$ has high surface energy compared to other faces [14]. ZnO grows faster in [0001] direction forming nanoflowers type morphology when the reaction was performed without the surfactant.

The formation of nanodumbbells morphology in addition of SDS can be clearly observed. Figure 7 shows the typical shape of a crystallization curve for a $\mathrm{ZnO}$ where the evolution of the crystal-length is plotted as a function of the concentration of SDS. The growth rate and nucleation of crystal are greatly affected by the SDS. Formation of dumbbell shape morphology was demonstrated by various researchers [1517]. Wang et al. reported the dumbbell-like twinning crystal, 


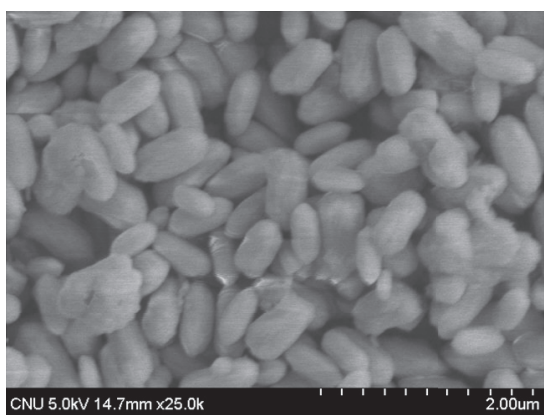

(a)

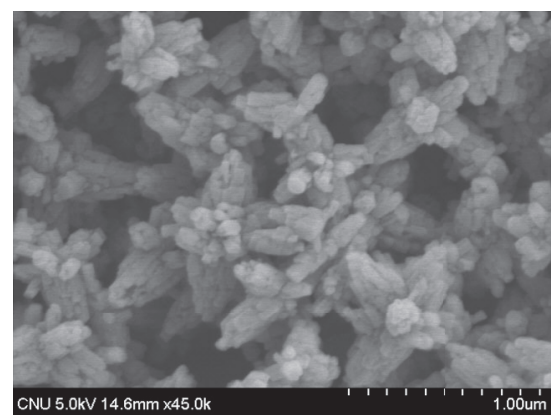

(b)

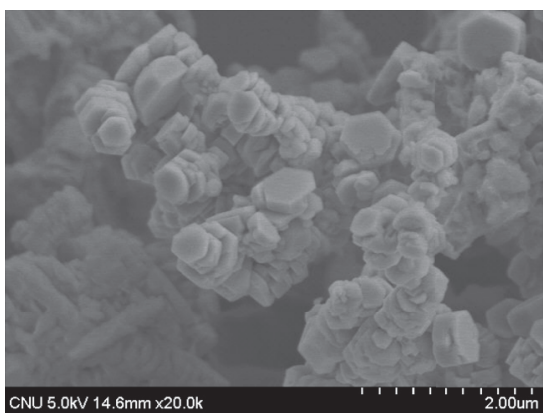

(c)

FIGURE 4: Typical FESEM images of $\mathrm{ZnO}$ nanostructures grown with SDS polymer $(0.1 \mathrm{~g})$ and different $\mathrm{NH}_{4} \mathrm{OH}$ concentrations of (a) $0.1 \mathrm{ml}$, (b) $1.0 \mathrm{ml}$, and (c) $2.0 \mathrm{ml}$ and growth temperature and growth time of $150^{\circ} \mathrm{C}$ and 10 hours, respectively.

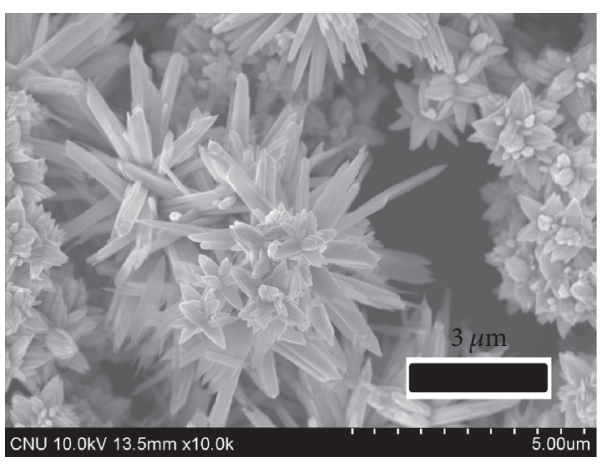

(a)

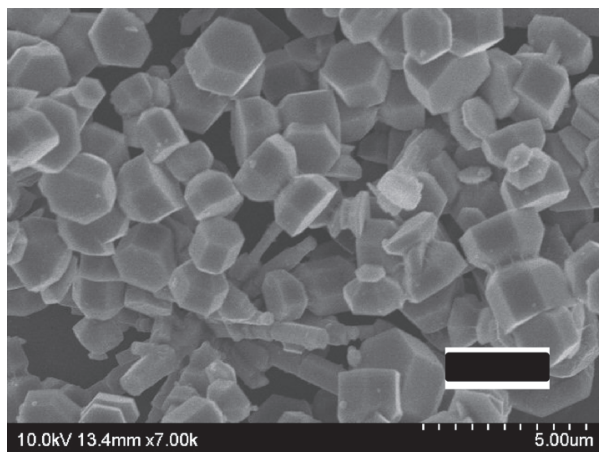

(c)

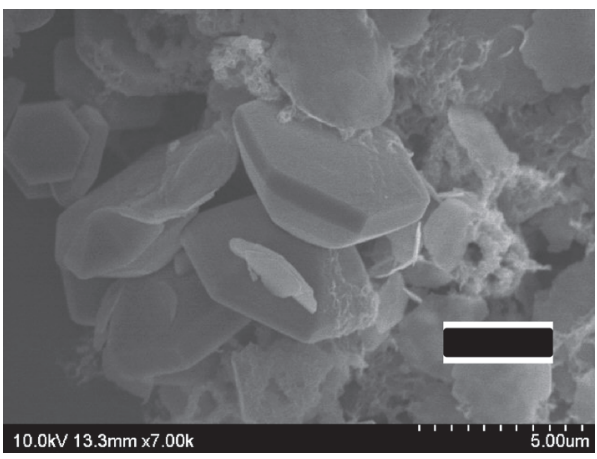

(e)

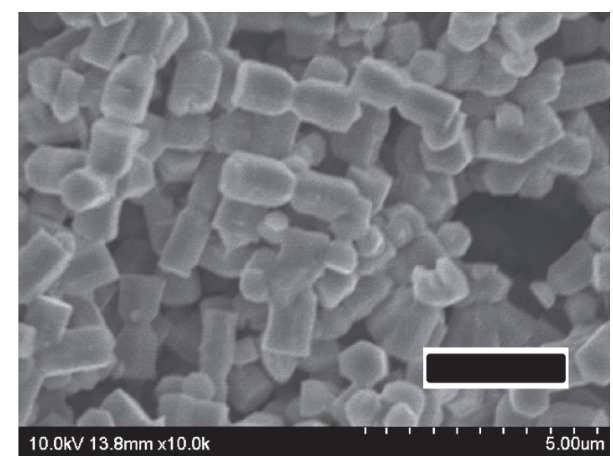

(b)

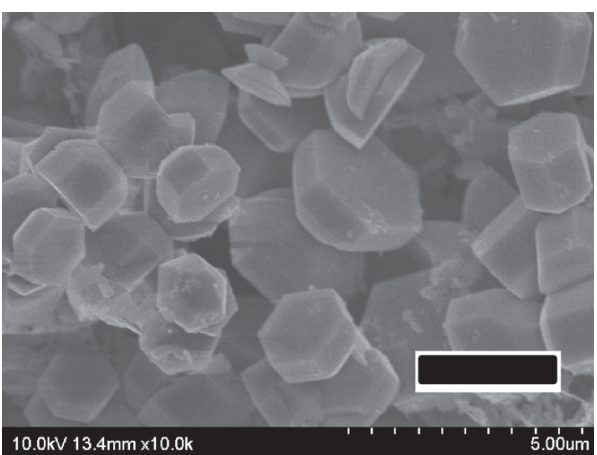

(d)

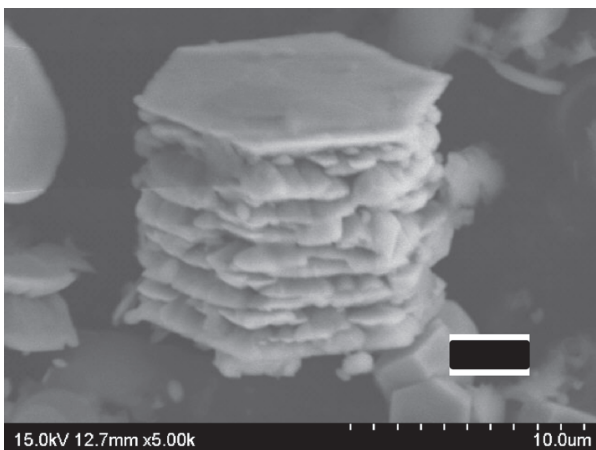

(f)

FIGURE 5: Typical FESEM images of $\mathrm{ZnO}$ nanostructures grown with different SDS surfactant concentrations of (a) $0 \mathrm{~g}$, (b) $0.1 \mathrm{~g}$, (c) $0.2 \mathrm{~g}$, (d) $0.3 \mathrm{~g}$, (e) $0.4 \mathrm{~g}$, and (f) $0.5 \mathrm{~g}$. 


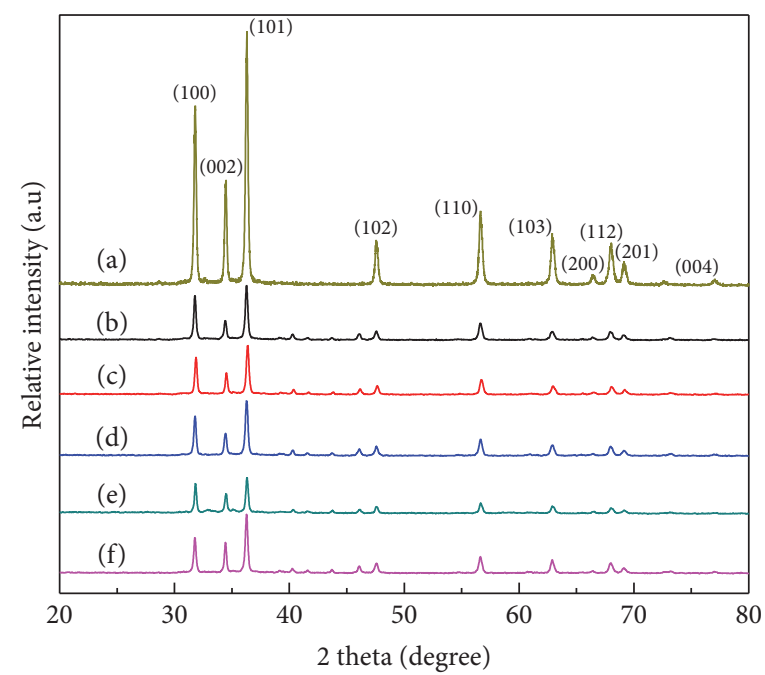

FIGURE 6: X-ray diffraction plot of $\mathrm{ZnO}$ nanostructures grown with different SDS surfactant concentrations of (a) $0 \mathrm{~g}$, (b) $0.1 \mathrm{~g}$, (c) $0.2 \mathrm{~g}$, (d) $0.3 \mathrm{~g}$, (e) $0.4 \mathrm{~g}$, and (f) $0.5 \mathrm{~g}$.

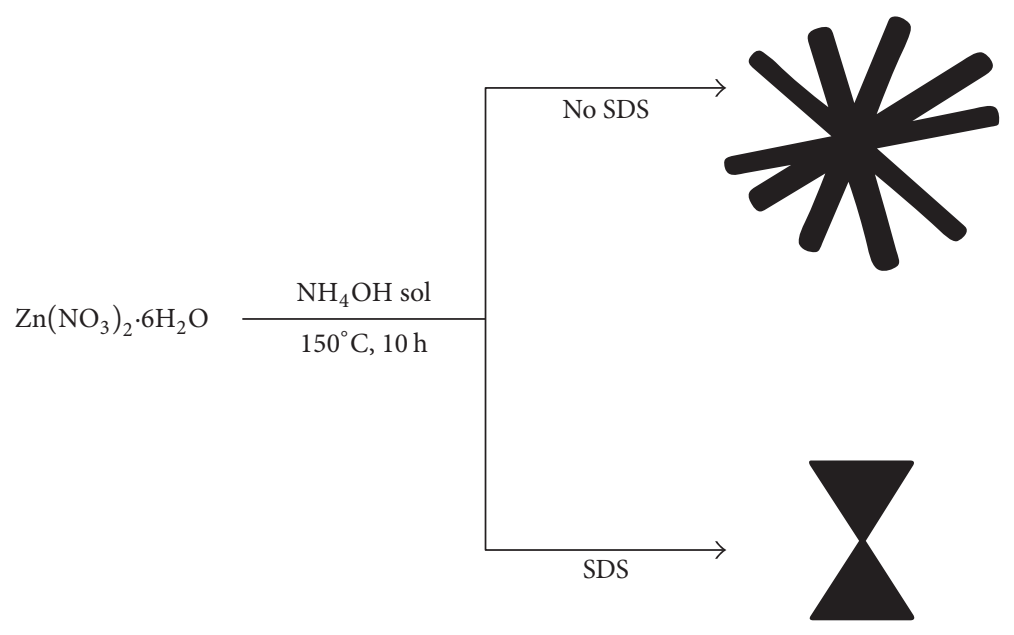

(a)

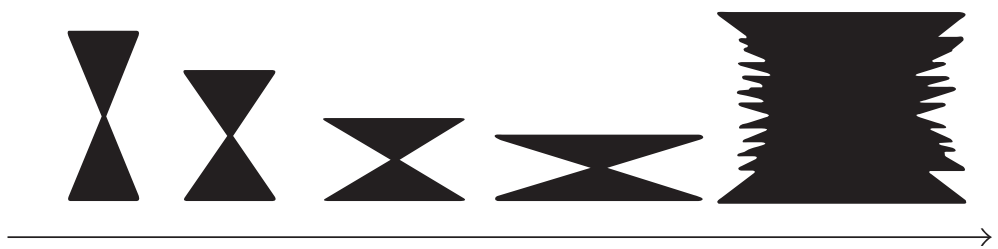

Increase in the concentration of SDS

(b)

FIGURE 7: (a) Schematic presentation of formation of $\mathrm{ZnO}$ nanodumbbells and (b) changes of nanodumbbells size as function of amount of SDS surfactant.

in which $\mathrm{ZnO}_{4}{ }^{6-}$ growth units bond bridge between them in the presence of $\mathrm{K}^{+}$or $\mathrm{Na}^{+}$ions and grow along the [0001] direction [18]. Li et al. explained the possibility of formation of dumbbell by the electrostatic attraction between $\mathrm{ZnO}$ nuclei along (0001) face and the negatively charged sulphate groups of the SDS and slows the growth rate, since crystal will grow along the (000-1) face [19], which according to $\mathrm{ZnO}$ velocities of growth rate of faces is the slowest face [20]. On the basis of the experimental results we obtained, we think that the growth of the nanodumbbell is uneven, and both dumbbells are not equal in size. In our case, twining starts from formation of growth template by SDS and dumbbell size increased with SDS concentration [21]. According to Shi et al., NMR experiments show that, with increasing in the temperature, SDS aggregates to form large uniform circular disks and the size of the disk increases with the concentration of the 


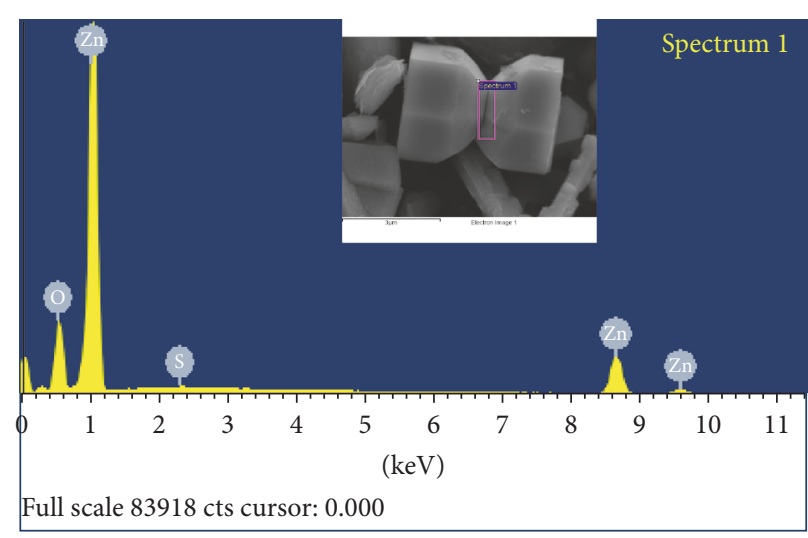

(a)

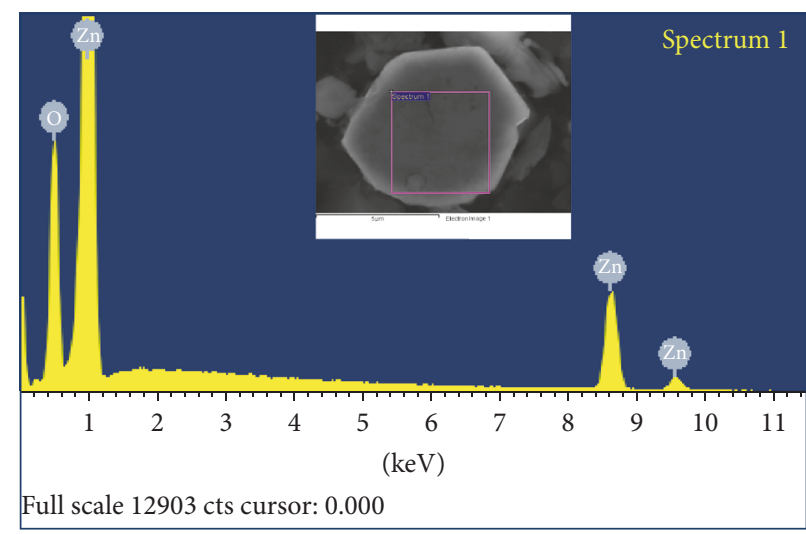

(b)

FIGURE 8: EDX spectra of ZnO nanodumbbells measured at different surfaces: (a) the twin junction and (b) basal plan of ZnO dumbbell.

SDS in the solution. In this process, disk shapes $\mathrm{SD}-\left(\mathrm{SO}_{4}{ }^{2-}\right)$ get attracted to the (0001) face of $\mathrm{ZnO}$ from a twin structure and the SD- is sandwiched between two (0001) faces and $\mathrm{ZnO}$ crystal growth takes place along (000-1) faces. To confirm it and to see if there is any sulfur incorporation in the twin junction, we observed the EDX spectra. Figure 8 shows the EDX spectra of twin junction and (000-1) faces of $\mathrm{ZnO}$ dumbbell. It was noticed that sulfur (atomic\% 0.3) was present in the twin junction and EDX spectra taken on the (000-1) faces, we only see $\mathrm{Zn}$ and $\mathrm{O}$ composition, and atomic\% of $\mathrm{O}(56 \%)$ is more that $\mathrm{Zn}(43 \%)$, which indicates (000-1) face. The growth takes place along (000-1) faces and surface adsorbed $\mathrm{Na}^{+}$ions reduce the growth rate of the faces by hindering the steps on the crystal surface, thereby increasing the surface area of the hindered face, finally forming dumbbells.

\section{Conclusions}

$\mathrm{ZnO}$ nanodumbbells nano/macrostructures were grown with the help of anionic surfactant sodium dodecyl sulphate (SDS). It is observed that SDS affects the $\mathrm{ZnO}$ morphology by selective adsorption on the crystal faces and size selective growth of nanodumbbells can be grown by controlling the SDS concentration. Our approach can be a novel way for growing $\mathrm{ZnO}$ dumbbells with different size for a wide range of applications.

\section{Conflicts of Interest}

The authors declare that they have no conflicts of interest.

\section{Acknowledgments}

This study was fully funded by Kumoh National Institute of Technology, Republic of Korea. The authors would like to acknowledge the support of Ministry of Trade, Industry and Energy (MOTIE) Project 10063553 in 2016. The authors would also like to acknowledge and are thankful to WC 300
Project by Business for Global Cooperative R\&D by Korea Small and Medium Business Administration in 2015.

\section{References}

[1] A. Wolcott, W. A. Smith, T. R. Kuykendall, Y. Zhao, and J. Z. Zhang, "Photoelectrochemical study of nanostructured Zno thin films for hydrogen generation from water splitting," Advanced Functional Materials, vol. 19, no. 12, pp. 1849-1856, 2009.

[2] H. M. Chen, C. K. Chen, Y.-C. Chang et al., "Quantum dot monolayer sensitized $\mathrm{ZnO}$ nanowire-array photoelectrodes: True efficiency for water splitting," Angewandte Chemie International Edition, vol. 49, no. 34, pp. 5966-5969, 2010.

[3] M. H. Huang, S. Mao, H. Feick et al., "Room-temperature ultraviolet nanowire nanolasers," Science, vol. 292, no. 5523, pp. 1897-1899, 2001.

[4] D. W. Chu, Y. Masuda, T. Ohji, and K. Kato, "Formation and photocatalytic application of $\mathrm{ZnO}$ nanotubes using aqueous solution," Langmuir, vol. 26, no. 4, pp. 2811-2815, 2010.

[5] B. V. Kumar, H. S. B. Naik, D. Girija, and B. V. Kumar, "ZnO nanoparticle as catalyst for efficient green one-pot synthesis of coumarins through Knoevenagel condensation," Journal of Chemical Sciences, vol. 123, no. 5, pp. 615-621, 2011.

[6] W. Guo, T. Liu, H. Zhang et al., "Gas-sensing performance enhancement in $\mathrm{ZnO}$ nanostructures by hierarchical morphology," Sensors and Actuators, B: Chemical, vol. 166-167, pp. 492499, 2012.

[7] M. Law, L. E. Greene, J. C. Johnson, R. Saykally, and P. Yang, "Nanowire dye-sensitized solar cells," Nature Materials, vol. 4, no. 6, pp. 455-459, 2005.

[8] S. K. Arya, S. Saha, J. E. Ramirez-Vick, V. Gupta, S. Bhansali, and S. P. Singh, "Recent advances in $\mathrm{ZnO}$ nanostructures and thin films for biosensor applications: review," Analytica Chimica Acta, vol. 737, pp. 1-21, 2012.

[9] J. Zhang, H. Liu, Z. Wang, N. Ming, Z. Li, and A. S. Biris, "Polyvinylpyrrolidone-directed crystallization of $\mathrm{ZnO}$ with tunable morphology and band gap," Advanced Functional Materials, vol. 17, no. 18, pp. 3897-3905, 2007.

[10] H. Tang, J. C. Chang, Y. Shan, and S.-T. Lee, "Surfactant-assisted alignment of $\mathrm{ZnO}$ nanocrystals to superstructures," Journal of Physical Chemistry B, vol. 112, no. 13, pp. 4016-4021, 2008. 
[11] M. Kurtz, J. Strunk, O. Hinrichsen et al., "Active sites on oxide surfaces: ZnO-catalyzed synthesis of methanol from $\mathrm{CO}$ and $\mathrm{H}_{2}$," Angewandte Chemie - International Edition, vol. 44, no. 18, pp. 2790-2794, 2005.

[12] J. Bao, Z. Liu, Y. Zhang, and N. Tsubaki, "Preparation of mesoporous $\mathrm{Cu} / \mathrm{ZnO}$ catalyst and its application in low-temperature methanol synthesis," Catalysis Communications, vol. 9, no. 5, pp. 913-918, 2008.

[13] S. A. French, A. A. Sokol, S. T. Bromley, C. R. A. Catlow, and P. Sherwood, "Identification and characterization of active sites and their catalytic processes - The $\mathrm{Cu} / \mathrm{ZnO}$ methanol catalyst," Topics in Catalysis, vol. 24, no. 1-4, pp. 161-172, 2003.

[14] G. Y. Krasnikov and V. P. Bokarev, "Surface energy and crystal faceting of elemental semiconductors and other substances," Doklady Physical Chemistry, vol. 382, no. 1-3, pp. 14-17, 2002.

[15] Q. Yu, C. Yu, H. Yang et al., "Growth of dumbbell-like $\mathrm{ZnO}$ microcrystals under mild conditions and their photoluminescence properties," Inorganic Chemistry, vol. 46, no. 15, pp. 62046210, 2007.

[16] H. Jiang, J. Hu, F. Gu, and C. Li, "Self-assembly of solid or tubular $\mathrm{ZnO}$ rods into twinning microprisms via a hydrothermal route," Journal of Alloys and Compounds, vol. 478, no. 1-2, pp. 550-553, 2009.

[17] Y. Peng, A.-W. Xu, B. Deng, M. Antonietti, and H. Cölfen, "Polymer-controlled crystallization of zinc oxide hexagonal nanorings and disks," Journal of Physical Chemistry B, vol. 110, no. 7, pp. 2988-2993, 2006.

[18] B. G. Wang, E. W. Shi, and W. Z. Zhong, "Twinning morphologies and mechanisms of $\mathrm{ZnO}$ crystallites under hydrothermal conditions," Crystal Research and Technology, vol. 33, no. 6, pp. 937-941, 1997.

[19] P. Li, Y. Wei, H. Liu, and X.-K. Wang, "Growth of well-defined $\mathrm{ZnO}$ microparticles with additives from aqueous solution," Journal of Solid State Chemistry, vol. 178, no. 3, pp. 855-860, 2005.

[20] W.-J. Li, E.-W. Shi, W.-Z. Zhong, and Z.-W. Yin, "Growth mechanism and growth habit of oxide crystals," Journal of Crystal Growth, vol. 203, no. 1, pp. 186-196, 1999.

[21] L. Shi, X. Wu, L. Lu, X. Yang, and X. Wang, "Molecular mechanism for formation of polyaniline lamella from a lyotropic liquid crystal: An NMR study," Journal of Physical Chemistry B, vol. 113, no. 9, pp. 2725-2733, 2009. 

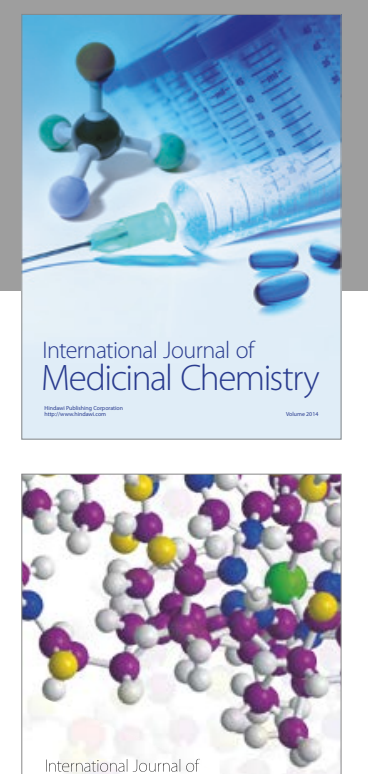

Carbohydrate Chemistry

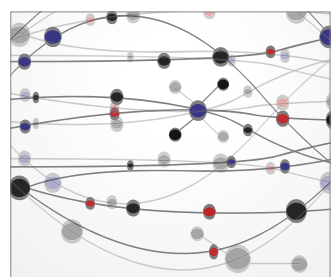

The Scientific World Journal
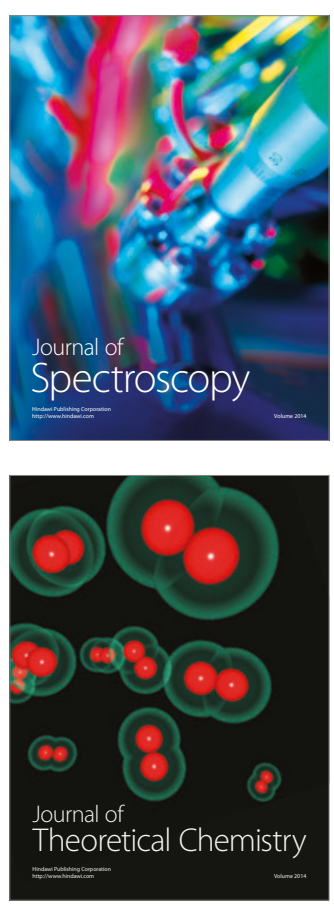
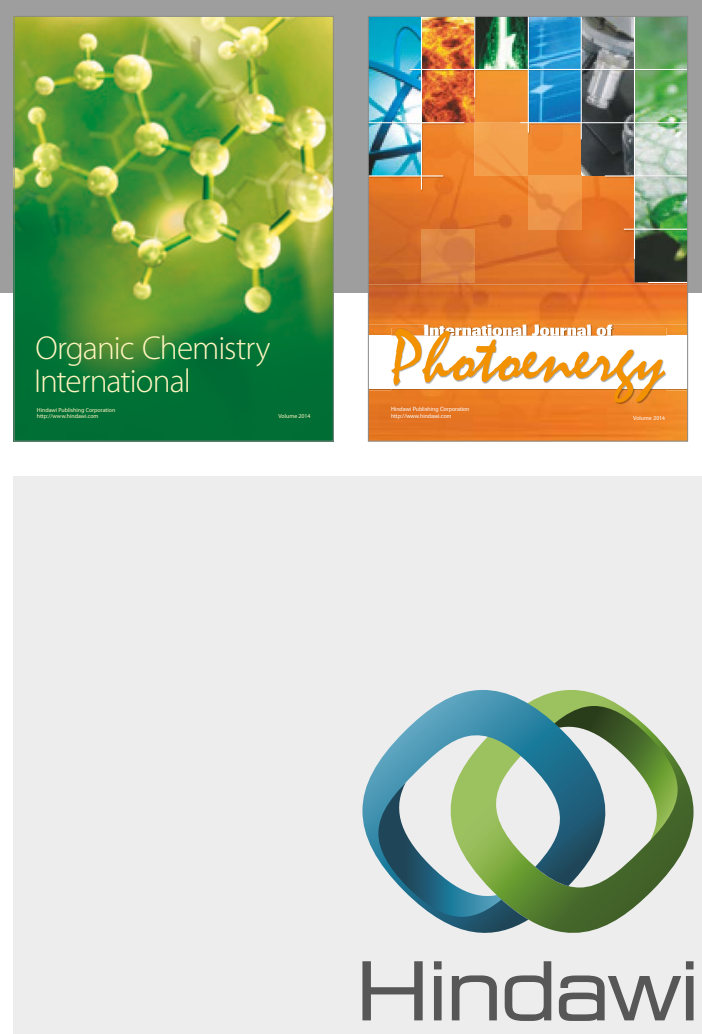

Submit your manuscripts at

https://www.hindawi.com

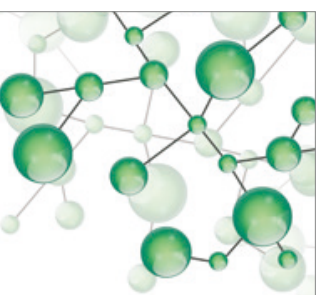

International Journal of

Inorganic Chemistry

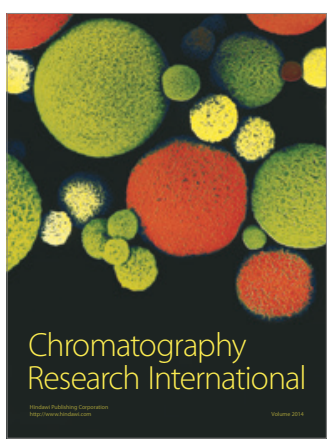

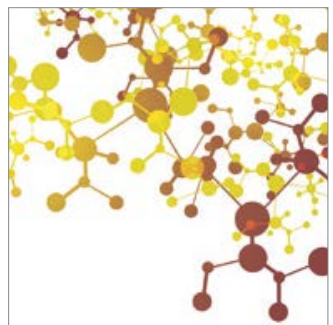

Applied Chemistry
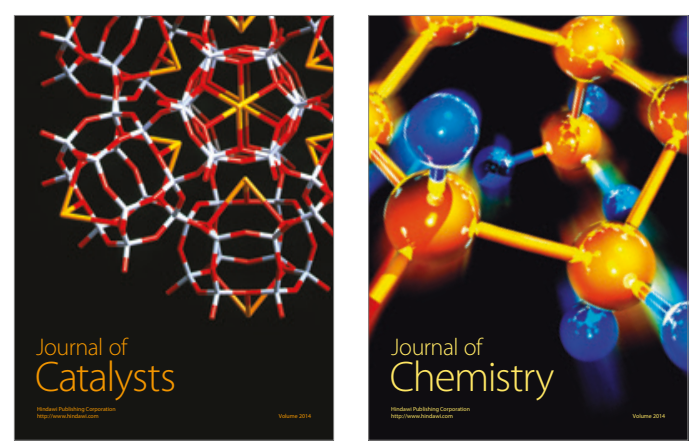
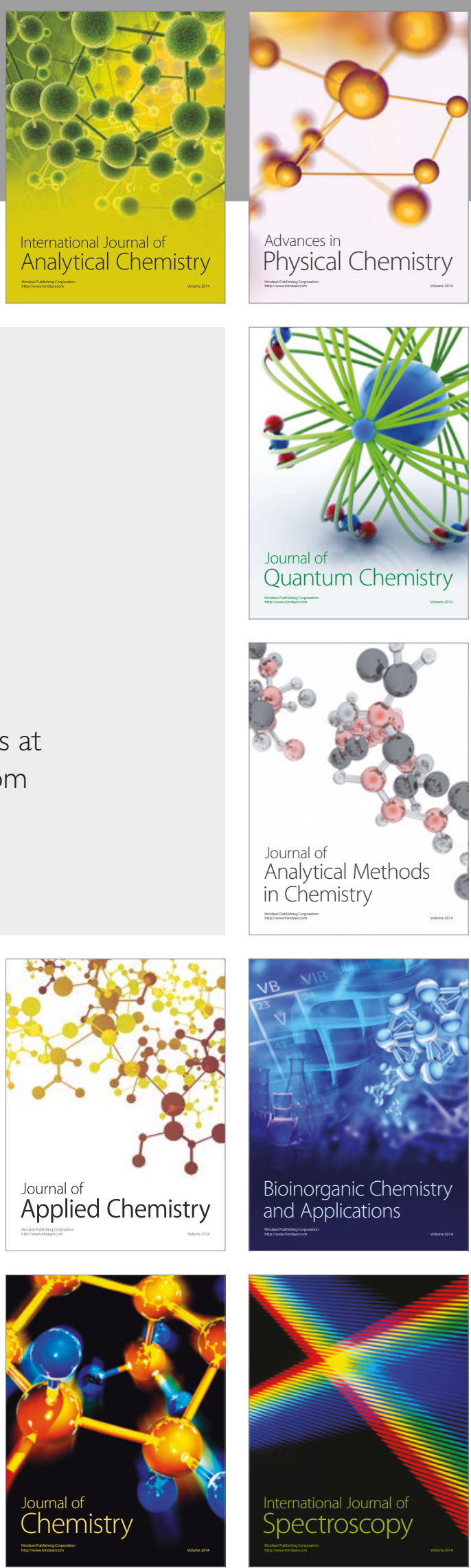